\title{
Direct Fabrication of Cobalt Oxide Nanoparticles Employing Sucrose as a Combustion Fuel
}

\author{
M. Th. Makhlouf, B. M. Abu-Zied, and T. H. Mansoure \\ Department of Chemistry, Faculty of Science, Assiut University, Assiut 71516, Egypt \\ Correspondence should be addressed to B. M. Abu-Zied; babuzied@yahoo.com
}

Received 30 November 2012; Accepted 4 February 2013

Academic Editor: Raphael Schneider

Copyright (C) 2013 M. Th. Makhlouf et al. This is an open access article distributed under the Creative Commons Attribution License, which permits unrestricted use, distribution, and reproduction in any medium, provided the original work is properly cited.

\begin{abstract}
Combustion method has been used as a fast and facile method to prepare nanocrystalline $\mathrm{Co}_{3} \mathrm{O}_{4}$ spinel employing sucrose as a combustion fuel. The products were characterized by thermal analyses (TGA and DTA), X-ray diffraction technique (XRD), Fourier transform infrared spectroscopy (FTIR), scanning electron microscopy (SEM), and transmission electron microscopy (TEM) techniques. Experimental results revealed that the molar ratio of fuel/oxidizer (F/O) plays an important role in controlling the crystallite size of $\mathrm{Co}_{3} \mathrm{O}_{4}$ nanoparticles. Transmission electron microscopy indicated that the crystallite size of $\mathrm{Co}_{3} \mathrm{O}_{4}$ nanocrystals was in the range of $13-32 \mathrm{~nm}$. X-ray diffraction confirmed the formation of $\mathrm{CoO}$ phase with spinel $\mathrm{Co}_{3} \mathrm{O}_{4}$. The effect of calcination temperature on crystallite size and morphology has been, also, discussed.
\end{abstract}

\section{Introduction}

Spinel cobalt oxide $\left(\mathrm{Co}_{3} \mathrm{O}_{4}\right)$, an important antiferromagnetic $p$-type semiconductor, is a technologically important and functional material, owing to its unique structure, intriguing properties, and potential practical applications in several important technological fields such as heterogeneous catalysis [1], solid state sensors [2], electrochromic sensors [3], anode materials in Li ion rechargeable batteries [4], energy storage [5], pigments and [6]. It is well known that the morphology and size of $\mathrm{Co}_{3} \mathrm{O}_{4}$ have a great influence on its properties, which are thus a key factor to their ultimate performance and applications. In this regard, it is desirable to tailorsynthesize nanoparticles with predesigned morphology and size distributions. $\mathrm{Co}_{3} \mathrm{O}_{4}$ with nanosized high surface area is expected to lead to even more attractive applications in conjunction of their traditional arena and nanotechnology [7]. Therefore, it is important to prepare $\mathrm{Co}_{3} \mathrm{O}_{4}$ with defined morphologies and a narrow range of size distribution.

Much effort has been made to synthesize nanocrystalline $\mathrm{Co}_{3} \mathrm{O}_{4}$, with various particle sizes, from economical and practical aspects point of view including thermal decomposition of cobalt oxalate $(60-200 \mathrm{~nm})$ [8], one-pot hydrothermal reaction (average size $30 \mathrm{~nm}$ ) [9], thermal decomposition of sol-gel derived oxalates $(15-20 \mathrm{~nm})$ [10], and solution combustion method (23-90 nm) [11]. Focusing our attention to the combustion route, it involves a self-sustained reaction between an oxidizer (e.g., metal nitrate) and a fuel (e.g., urea, sucrose, glycine, and hydrazides). This process not only yields nanosize oxide materials, but also allows uniform (homogeneous) doping of trace amounts of rare-earth impurity ions in a single step. In addition, there are some reports involving the synthesis of $\mathrm{Co}_{3} \mathrm{O}_{4}$ nanocrystallites with various morphologies using combustion method. For instance, $\mathrm{Co}_{3} \mathrm{O}_{4}$ nanocrystallites with different morphologies such as cubic $(10-50 \mathrm{~nm})$ [7] and foamy porous (average size $67 \mathrm{~nm}$ ) [12] morphology were obtained by solution combustion method. Moreover, Toniolo et al. [11] have prepared nanocrystalline $\mathrm{Co}_{3} \mathrm{O}_{4}$ with crystallites sizes from 23 to $90 \mathrm{~nm}$ employing urea and glycine as combustion fuels. Jiu et al. [13] have prepared nanocrystalline $\mathrm{Co}_{3} \mathrm{O}_{4}$ with crystallites sizes of $33 \mathrm{~nm}$ employing polyvinyl alcohol (PVA) as combustion fuel using polymer combustion method.

Metal ions can be uniformly distributed in molecular scale through polyfunctional groups (e.g., $-\mathrm{COOH},-\mathrm{NH}_{2}$, $\mathrm{OH}$, etc.) from chelating ligands such as citric acid, glycine [14], ethylenediaminetetraacetic acid (EDTA), and polyacrylate [15] to form organic matrices. Thermal decomposition 
of the matrices provides fine particles at reasonably lower temperature. Sucrose is a type of water-soluble and inexpensive agricultural product. In the acidic condition, $-\mathrm{COOH}$ and $-\mathrm{OH}$ groups can be generated, which hence can form stable binding with metal ions in homogeneous solution. Therefore, sucrose can also act as an effective chelating agent like citric acid to produce fine particles [16]. In recent years, attempts have been made by several researchers to prepare nanopowders using sucrose as a chelating agent and fuel [17-19]. Das et al. [17] synthesized single phase $\alpha$-alumina nanocrystallites with high surface area at a low temperature of $600^{\circ} \mathrm{C}$. Lazarraga et al. [18] obtained nanosized $\mathrm{LiNi}_{y} \mathrm{Mn}_{2-y} \mathrm{O}_{4}$ spinels for rechargeable lithium batteries.

To our knowledge, there is a lack of information concerning the synthesis of $\mathrm{Co}_{3} \mathrm{O}_{4}$ nanoparticles using sucrose as a combustion fuel. Accordingly, in this work, we report a novel chemical route for the preparation of $\mathrm{Co}_{3} \mathrm{O}_{4}$ nanoparticles via combustion synthesis using sucrose as a combustion fuel and cobalt nitrate as an oxidizer. The process involves dehydration of a Co ion-sucrose complex solution, followed by the decomposition of the obtained product. Complete dehydration of the complex solution to dryness produces a black precursor mass. Heat treatment of the dried precursor mass in a furnace air environment results in a voluminous, crushable, highly fragile phase-pure nanocrystalline $\mathrm{Co}_{3} \mathrm{O}_{4}$. Decomposition of sucrose generates excess heat and huge amounts of gases that help to produce the porosity in the final product. These characteristics, together with the watersoluble nature of sucrose, have motivated the initiation of the present study. The effect of the fuel-to-oxidizer molar ratio as well as calcination temperature on controlling particle size of the product was investigated. The textural and structure properties of the prepared $\mathrm{Co}_{3} \mathrm{O}_{4}$ nanoparticles were characterized by means of thermal analyses (TGA and DTA), X-ray powder diffraction (XRD), Fourier transform infrared spectroscopy (FT-IR), and electron microscopy (SEM and TEM).

\section{Experimental}

2.1. Preparation Procedure. Cobalt nitrate, $\mathrm{Co}\left(\mathrm{NO}_{3}\right)_{2} \cdot 6 \mathrm{H}_{2} \mathrm{O}$, and sucrose, $\left(\mathrm{C}_{12} \mathrm{H}_{22} \mathrm{O}_{11}\right)$, were of analytical grade reagents and were used without further purification. Distilled water was used in all of preparations. Two series of samples were prepared. In the first one (series I), we have investigated the effect of changing the sucrose/cobalt nitrate molar ratios $(\mathrm{F} / \mathrm{O}), 0.5,1,2,5,8$, and 16 , on the morphology and crystallite size of $\mathrm{Co}_{3} \mathrm{O}_{4}$. In a typical procedure, the required amounts of cobalt nitrate $(3.76 \mathrm{~g})$ and sucrose $(2.21,4.42$, 8.84, 22.1, 35.36, 70.72 g, and resp.) were weighed to the nearest milligram. Cobalt nitrate and sucrose were dissolved in distilled water (total solutions volume was $100 \mathrm{~mL}$ ) to form a pink homogeneous solution; the solution was then heated on a hotplate at about $100^{\circ} \mathrm{C}$ to evaporate the excess water. After that the obtained viscous gel was calcined in muffle furnace at $400^{\circ} \mathrm{C}$ for $3 \mathrm{~h}$ in a static air atmosphere. In series II, we have investigated the effect of changing the calcination temperature, $350-1000^{\circ} \mathrm{C}$, employing the same procedure at sucrose/cobalt nitrate molar ratio of 0.5 .

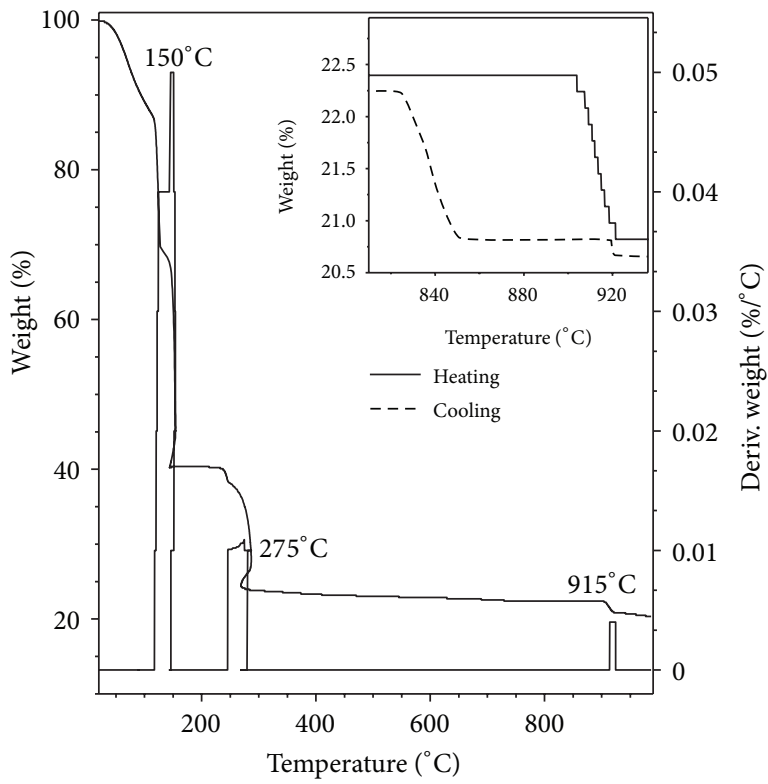

FIGURE 1: TGA and DTG curves obtained by heating the dried precursor having $\mathrm{F} / \mathrm{O}$ equals to 0.5 in air atmosphere as a carrier gas.

2.2. Characterization. Simultaneous TGA and DTA curves were recorded with a Shimadzu DTG-60 instrument apparatus using a heating rate of $10^{\circ} \mathrm{C} \mathrm{min}{ }^{-1}$ in air atmosphere (flow rate at $40 \mathrm{~mL} / \mathrm{min}$ ). Powder X-ray diffraction (XRD) patterns were recorded using Philips diffractometer (type PW $103 / 00)$ with $\mathrm{CuK} \alpha$ radiation $(\lambda=1.5405 \AA$ ) at $35 \mathrm{kV}$ and $20 \mathrm{~mA}$ with a scanning rate in $2 \theta$ of $0.06^{\circ} \mathrm{min}^{-1}$. FTIR spectra were performed employing the $\mathrm{KBr}$ disc technique in the wavelength range of $4000-400 \mathrm{~cm}^{-1}$, using Thermo-Nicolet6700 FTIR spectrophotometer. Scanning electron micrographs were obtained using a JEOL scanning microscope (model JSM-5400 LV). Transmission electron pictures were taken using JEOL transmission microscope (model JEMTH100 II).

\section{Results and Discussion}

3.1. Thermal Analysis. Figure 1 shows the weight loss (TG) and the associated derivative thermogram (DTG) of the precursor synthesized at $\mathrm{F} / \mathrm{O}$ equal to 0.5 in air atmosphere as a carrier gas. This figure manifests that the precursor underwent decomposition with increasing the temperature from ambient degree $1000^{\circ} \mathrm{C}$ in several steps. The first step starts from room temperature to around $115^{\circ} \mathrm{C}$ which brings a weight loss (WL) of $15 \%$. This step could be attributed to the dehydration of the parent mixture. TGA thermogram demonstrates the presence of two consecutive WL steps at the $115-165^{\circ} \mathrm{C}$ temperature range. Such steps could be ascribed to the decomposition of the precursor constituents as well as the combustion of the produced gases. Another step is located at $200-280^{\circ} \mathrm{C}$ temperature range which brings a weight loss of $16 \%$. Such step could be related to the completion 


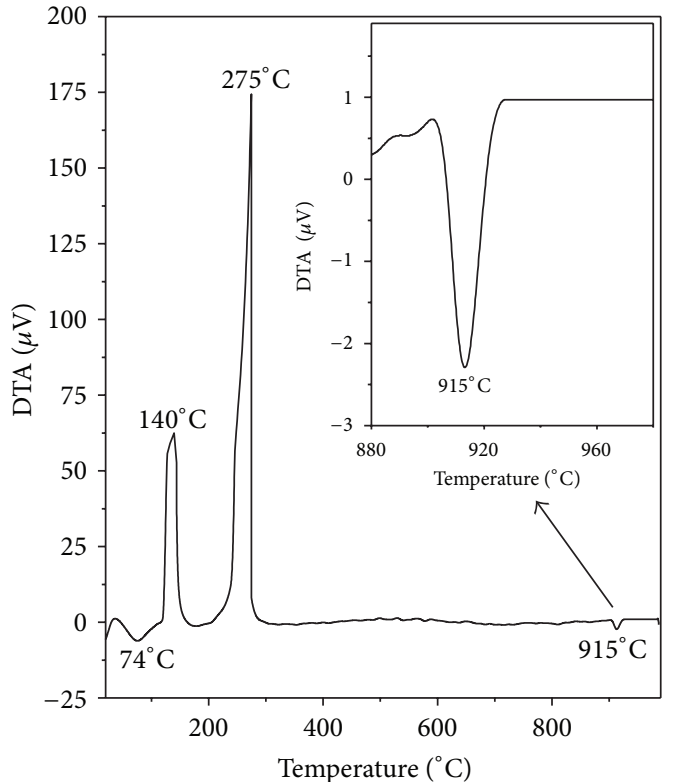

FIGURE 2: DTA thermogram obtained by heating the precursor (F/O equals to 0.5 ) in air atmosphere.

of the precursor decomposition and the formation of the nanocrystalline $\mathrm{Co}_{3} \mathrm{O}_{4}$. On further heating the precursor up to $1000^{\circ} \mathrm{C}$, one can observe a fifth step being maximized at $915^{\circ} \mathrm{C}$. This step is accompanied by weight loss of $1.6 \%$ due to the decomposition of $\mathrm{Co}_{3} \mathrm{O}_{4}$ into $\mathrm{CoO}$ according to [7]

$$
\mathrm{Co}_{3} \mathrm{O}_{4} \longrightarrow 3 \mathrm{CoO}+\frac{1}{2} \mathrm{O}_{2}
$$

The inserted curves in Figure 1 shows a magnification of both the heating and the cooling curves of the precursor from the $800^{\circ} \mathrm{C}$ to $940^{\circ} \mathrm{C}$ temperature range. It illustrates that the cooling of $\mathrm{CoO}$ phase formed at $915^{\circ} \mathrm{C}$, as a product of the decomposition of spinel $\mathrm{Co}_{3} \mathrm{O}_{4}$ phase, has a weight gain of $1.6 \%$. This weight gain could be attributed to the oxidation of $\mathrm{CoO}$ into $\mathrm{Co}_{3} \mathrm{O}_{4}$, and this, in turn, indicates the reversibility of (1).

Figure 2 shows the obtained DTA curve during heating the precursor with $\mathrm{F} / \mathrm{O}$ molar ratio of 0.5 in air atmosphere degree to $1000^{\circ} \mathrm{C}$. Inspection of this figure reveals the presence of an endothermic peak at the $74^{\circ} \mathrm{C}$. Such peak, associated with the first observed WL step in Figure 1, could be related to the dehydration of the precursor. In addition, the thermogram shows an exothermic peak at $140^{\circ} \mathrm{C}$. The temperature range of such peak is consistent with that of the second and third steps in the TGA pattern. This effect corresponds to simultaneous decomposition of $\mathrm{NO}_{3}{ }^{-}$and charring of sucrose. Simultaneously, sucrose is oxidized by nitrate anions (resulting in carbon dioxide, nitrogen, nitrogen dioxide and water [20]) releasing plenty of gases. Thus, the exothermic peak could be attributed to the superposition of precursor decomposition (endothermic) and combustion of the evolved gases (exothermic). It is clear that the combustion process predominates. Also, the thermogram shows another sharp

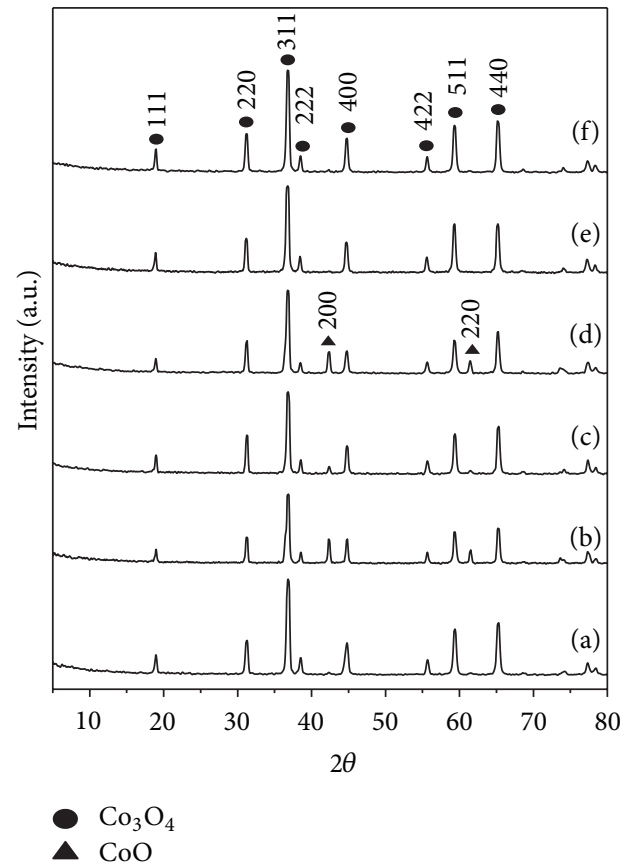

FIGURE 3: XRD patterns of nanocrystalline $\mathrm{Co}_{3} \mathrm{O}_{4}$ samples calcined at $400^{\circ} \mathrm{C}$ being prepared at different $\mathrm{F} / \mathrm{O}$ molar ratios: (a) 0.5 , (b) 1 , (c) 2, (d) 5, (e) 8, and (f) 16 .

exothermic peak at $275^{\circ} \mathrm{C}$. The temperature of such peak is consistent with that of the fourth WL step observed in the TGA pattern. This peak could be ascribed to the combustion of carbon and to the crystallization of spinel $\mathrm{Co}_{3} \mathrm{O}_{4}$. Going to the high temperature range, the obtained DTA thermogram manifests the presence of an endothermic peak at $915^{\circ} \mathrm{C}$. Such effect can be ascribed to the decomposition of $\mathrm{Co}_{3} \mathrm{O}_{4}$ into $\mathrm{CoO}$, that is, thermal reduction of $\mathrm{Co}^{3+}$ to $\mathrm{Co}^{2+}$.

3.2. X-Ray Diffraction. X-ray diffraction patterns of the as-prepared $\mathrm{Co}_{3} \mathrm{O}_{4}$ obtained via combustion synthesis at different sucrose/cobalt nitrate molar ratios (i.e., $0.5,1,2$, 5,8 , and 16) being calcined at $400^{\circ} \mathrm{C}$ is shown in Figure 3 (curves a-f), respectively. Inspection of this figure revealed that (i) when the $\mathrm{F} / \mathrm{O}$ molar ratio is 0.5 (pattern a), the powder after combustion contains only well crystallized cubic spinel $\mathrm{Co}_{3} \mathrm{O}_{4}$ (JCPDS card file no. 80-1545), (ii) when the F/O molar ratio is in the range of $1-5$ (patterns $\mathrm{b}-\mathrm{d}$ ), the powders are composed of a mixture of $\mathrm{Co}_{3} \mathrm{O}_{4}$ (JCPDS card file No. 801545) and CoO (JCPDS 78-0431), and (iii) when the F/O molar ratios are higher than 5 , again the powder diffraction patterns are composed only $\mathrm{Co}_{3} \mathrm{O}_{4}$ (JCPDS card file No. 801545 ) as in patterns e and $\mathrm{f}$.

In order to check the role of sucrose/cobalt nitrate molar ratio variation in controlling the structural parameters of the obtained nanocrystalline $\mathrm{Co}_{3} \mathrm{O}_{4}$, the lattice parameter $(a)$ and crystallite size $(D)$ were calculated. The lattice parameters were computed using the $d$-spacing values and the respective $(h k l)$ parameters. The obtained values are plotted in Figure 4(a) as a function of the sucrose/cobalt 


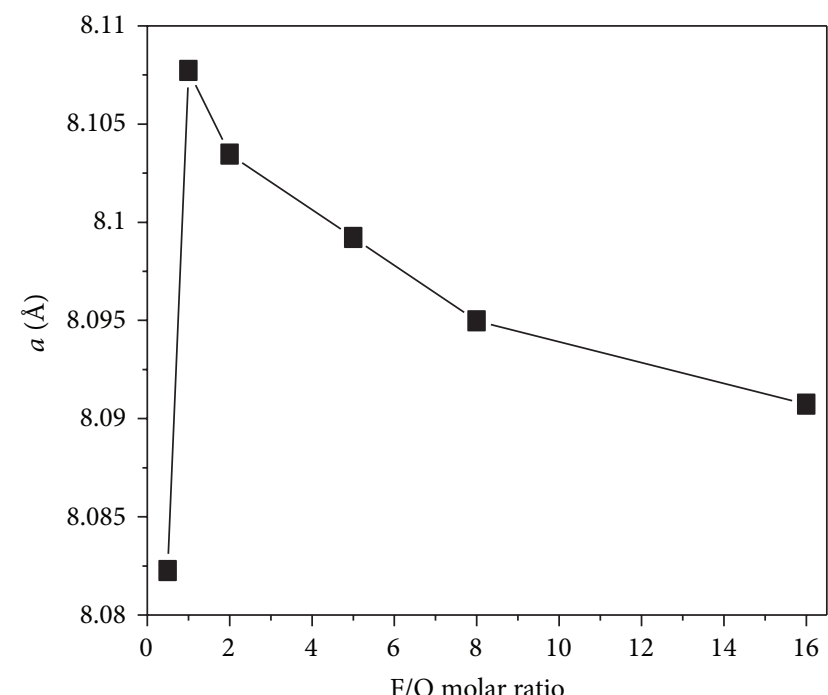

(a)

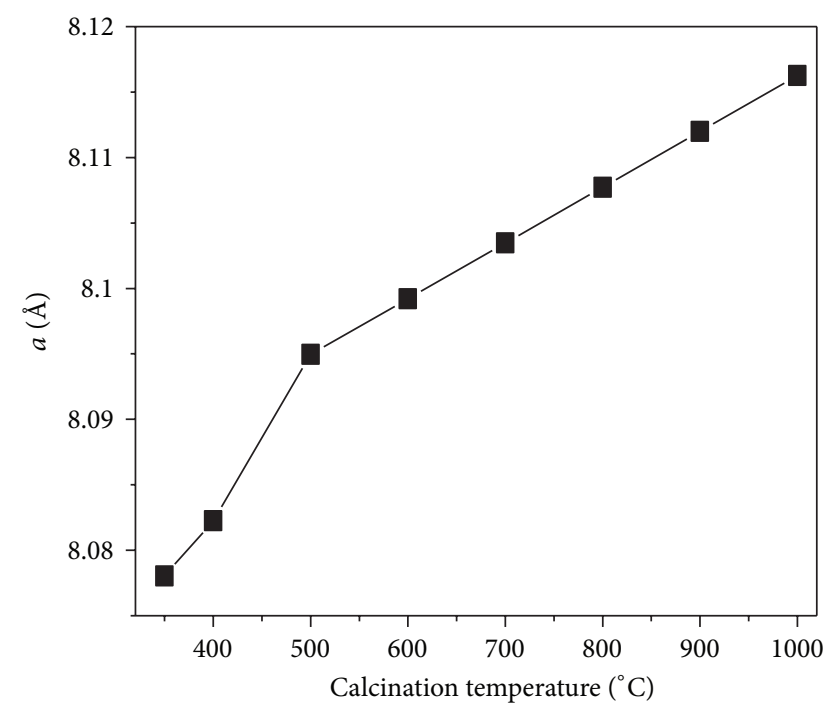

(b)

FIGURE 4: Effect of F/O molar ratios (a) and calcination temperature (b) on the lattice parameter values of nanocrystalline $\mathrm{Co}_{3} \mathrm{O}_{4}$.

nitrate molar ratio. The crystallite size $(D)$ was calculated using Scherrer equation [12] from the full-width at halfmaximum (FWHM) of the peaks. The relevant values are listed in Table 1. From Table 1, it is evident that the crystallite size of $\mathrm{Co}_{3} \mathrm{O}_{4}$ increased with increasing the sucrose/cobalt nitrate molar ratio from 0.5 till 1 , and then it shows a mild decrease upon further $\mathrm{F} / \mathrm{O}$ increase. This in turn indicates that is the lowest sucrose/cobalt nitrate value gets the smaller the $\mathrm{Co}_{3} \mathrm{O}_{4}$ crystallite size. Regarding the lattice parameter, it is obvious from Figure 4(a) that the variation of the lattice parameter with molar ratio follows the same trend as that observed for the crystallite size.

Since the $\mathrm{Co}_{3} \mathrm{O}_{4}$ obtained by using a molar ratio of 0.5 exhibits the lowest crystallite size, the study was extended to

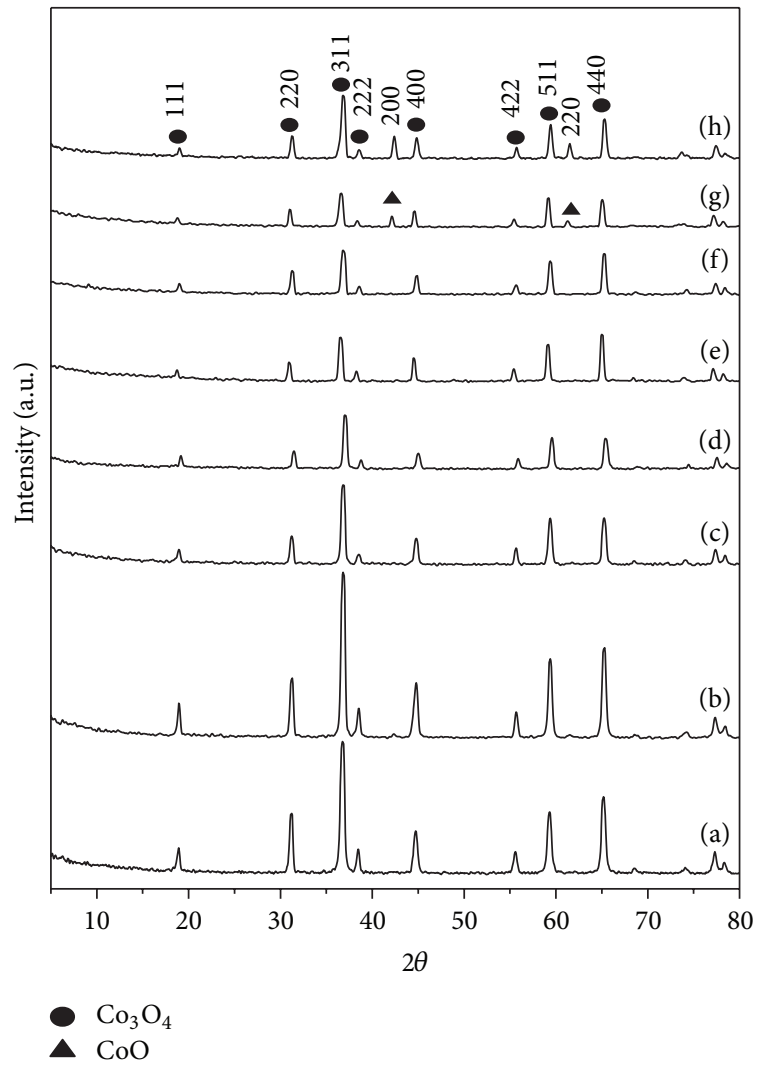

FIGURE 5: XRD patterns of nanocrystalline $\mathrm{Co}_{3} \mathrm{O}_{4}$ samples obtained via $\mathrm{F} / \mathrm{O}$ molar ratio of 0.5 at different calcination temperature: (a) 350, (b) 400, (c) 500, (d) 600, (e) 700, (f) 800, (g) 900, and (h) $1000^{\circ} \mathrm{C}$.

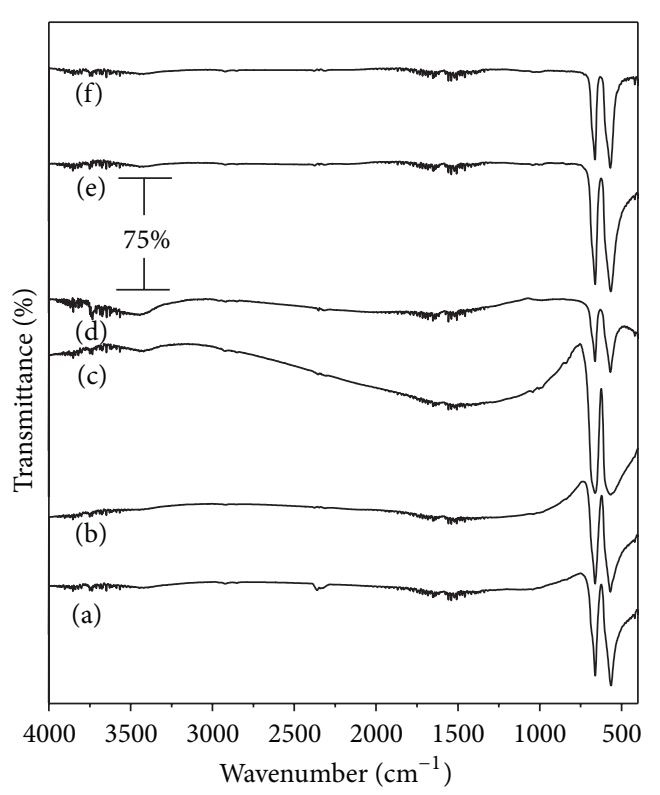

FIGURE 6: FTIR spectra of as-prepared nanocrystalline $\mathrm{Co}_{3} \mathrm{O}_{4}$ at different F/O molar ratios: (a) 0.5 , (b) 1 , (c) 2 (d) 5, (e) 8 , and (f) 16. 


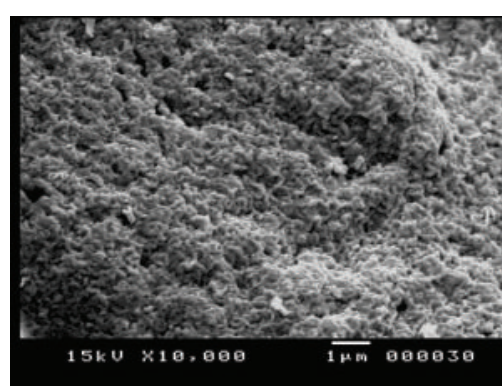

(a)

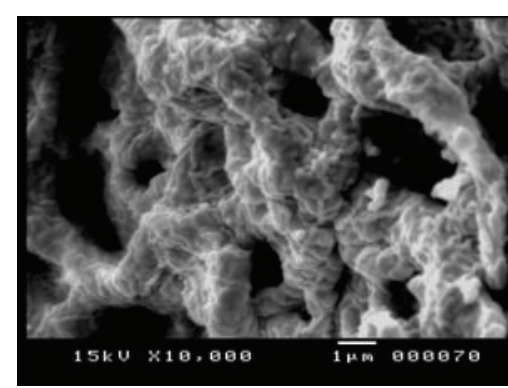

(b)

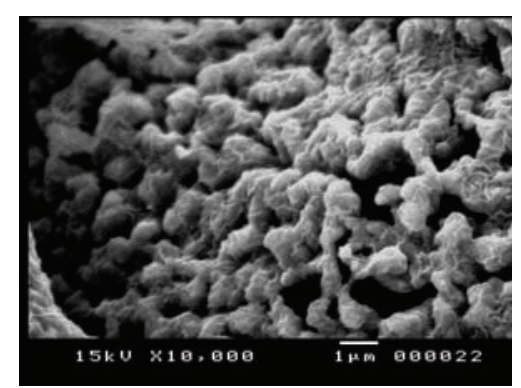

(c)

FIgURE 7: SEM of as-prepared nanocrystalline $\mathrm{Co}_{3} \mathrm{O}_{4}$ at different F/O molar ratios, (a) 0.5, (b) 1, and (c) 5, being calcined at $400^{\circ} \mathrm{C}$.

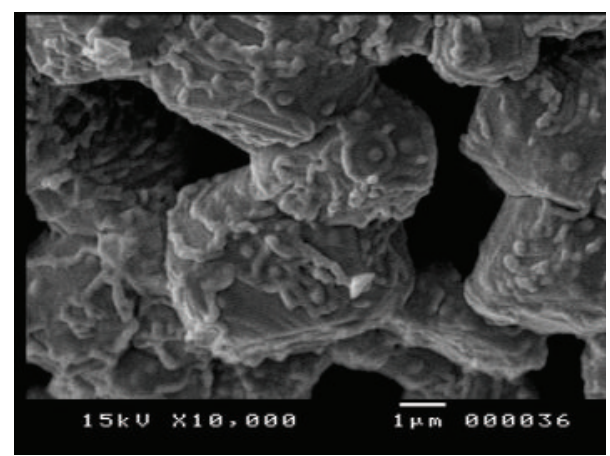

FIGURE 8: SEM of as-prepared nanocrystalline $\mathrm{Co}_{3} \mathrm{O}_{4}$ using sucroseto-cobalt nitrate molar ratio of 0.5 calcined at $1000^{\circ} \mathrm{C}$.

TABLE 1: Crystallite sizes of $\mathrm{Co}_{3} \mathrm{O}_{4}$ at different $\mathrm{F} / \mathrm{O}$ molar ratios being calcined at $400^{\circ} \mathrm{C}$.

\begin{tabular}{lcccccc}
\hline F/O molar ratio & 0.5 & 1 & 2 & 5 & 8 & 16 \\
Crystallite size $(\mathrm{nm})$ & 24.1 & 30.8 & 27.5 & 26.1 & 25.5 & 25 \\
\hline
\end{tabular}

check the influence of changing the calcination temperature on the morphology and crystallite size of nanocrystalline $\mathrm{Co}_{3} \mathrm{O}_{4}$ at this ratio. XRD patterns of the as-prepared $\mathrm{Co}_{3} \mathrm{O}_{4}$ obtained via calcining sucrose/cobalt nitrate parents having $\mathrm{F} / \mathrm{O}$ molar ratio of 0.5 at $350-1000^{\circ} \mathrm{C}$ temperature range are shown in Figure 5. From this figure, two points could be raised: (i) all diffraction peaks belong to one phase only $\left(\mathrm{Co}_{3} \mathrm{O}_{4}\right)$ at the calcination temperatures range $350-800^{\circ} \mathrm{C}$; however, a peak shift to lower angles with increasing the calcination temperature is evident indicating an expansion of the cubic lattice and (ii) the diffraction peaks related to $\mathrm{CoO}$ appear at high calcination temperatures (i.e., 900 or $1000^{\circ} \mathrm{C}$ ) which indicates that, $\mathrm{CoO}$ formed at high temperature via the thermal reduction of $\mathrm{Co}_{3} \mathrm{O}_{4}$ could not be oxidized completely to $\mathrm{Co}_{3} \mathrm{O}_{4}$ on cooling.

Table 2 gives the average crystallite size of $\mathrm{Co}_{3} \mathrm{O}_{4}$ phase at different calcination temperatures $\left(350-1000^{\circ} \mathrm{C}\right)$ calculated from XRD data, whereas the relevant lattice parameters are shown in Figure 4(b). From these data, one can state safely that the sample calcined at $350^{\circ} \mathrm{C}$ exhibits the lowest average crystallite size $(D=23.4 \mathrm{~nm})$. With increasing the calcination temperature, the average crystallite size is
TABle 2: Crystallite sizes of $\mathrm{Co}_{3} \mathrm{O}_{4}$ at $\mathrm{F} / \mathrm{O}$ molar ratio of $0.5: 1$ calcined at different calcinations temperature.

\begin{tabular}{lrlllllll}
\hline $\begin{array}{l}\text { Calcination } \\
\text { temperature }\left({ }^{\circ} \mathrm{C}\right)\end{array}$ & 350 & 400 & 500 & 600 & 700 & 800 & 900 & 1000 \\
$\begin{array}{l}\text { Crystallite size } \\
(\mathrm{nm})\end{array}$ & 23.4 & 24.1 & 24.7 & 25.6 & 26.7 & 27 & 27.9 & 30.3 \\
\hline
\end{tabular}

increased. This behavior was expected because the heating facilitates the diffusion and agglomeration of the particles [21-23]. Accordingly, we can conclude that the optimum conditions to obtain pure $\mathrm{Co}_{3} \mathrm{O}_{4}$ with the smallest crystallite size using sucrose as a fuel is sucrose/cobalt nitrate molar ratio of 0.5 and a calcination temperature at $350^{\circ} \mathrm{C}$.

\subsection{Fourier Transformation Infrared Spectroscopy (FTIR).} Cubic spinel structure of $\mathrm{Co}_{3} \mathrm{O}_{4}$ with $\mathrm{Co}^{2+}\left(3 \mathrm{~d}^{7}\right)$ and $\mathrm{Co}^{3+}$ $\left(3 \mathrm{~d}^{6}\right)$ located at tetrahedral and octahedral sites, respectively, belongs to the space group $(F d 3 m)$. The group theory predicts the following modes in the spinel: $\Gamma=A_{1 \mathrm{~g}}(\mathrm{R})+E_{\mathrm{g}}(\mathrm{R})+$ $F_{1 \mathrm{~g}}\left(\right.$ in) $+3 F_{2 \mathrm{~g}}(\mathrm{R})+2 A_{2 \mathrm{u}}$ (in) $+2 E_{\mathrm{u}}$ (in) $+4 F_{1 \mathrm{u}}$ (IR) $+2 F_{2 \mathrm{u}}$ (in), where (R), (IR), and (in) represent Raman active vibrations, infrared-active vibration, and inactive modes, respectively. The FT-IR spectra of as-prepared nanocrystalline $\mathrm{Co}_{3} \mathrm{O}_{4}$ at different $\mathrm{F} / \mathrm{O}$ molar ratios being calcined at $400^{\circ} \mathrm{C}$ are shown in Figure 6 (curves a-f). In the investigated region $\left(4000-400 \mathrm{~cm}^{-1}\right)$, the entire obtained spectra manifest the presence of two absorption bands at $565\left(v_{1}\right)$ and $661\left(v_{2}\right)$ $\mathrm{cm}^{-1}$ which originate from the stretching vibrations of the metal-oxygen bond and confirm the formation of $\mathrm{Co}_{3} \mathrm{O}_{4}$ spinel oxide $[1,8]$. The $v_{1}$ band is characteristic of $\mathrm{OB}_{3}$ (where $\mathrm{B}$ denotes the $\mathrm{Co}^{3+}$ in the octahedral hole) vibration, and the $v_{2}$ band is attributable to the $\mathrm{ABO}_{3}$ (where A denotes the $\mathrm{Co}^{2+}$ in the tetrahedral hole) vibration in the spinel lattice [12]. In addition, the FTIR spectra show no residual organic compounds and $\mathrm{NO}_{3}{ }^{-}$after calcination. It is worth noting that it is very difficult to differentiate between the FT-IR spectra of pure $\mathrm{Co}_{3} \mathrm{O}_{4}$ and that of $\mathrm{Co}_{3} \mathrm{O}_{4}$ with $\mathrm{CoO}$ impurities. Thus, the presence of some $\mathrm{CoO}$ impurities in the $\mathrm{Co}_{3} \mathrm{O}_{4}$ nanoparticles cannot be excluded based on analysis of FT-IR only. The FTIR spectra of nanocrystalline $\mathrm{Co}_{3} \mathrm{O}_{4}$ samples having sucrose/cobalt nitrate of 0.5 being calcined at $350-1000^{\circ} \mathrm{C}$ temperature range, not shown, exhibit two 


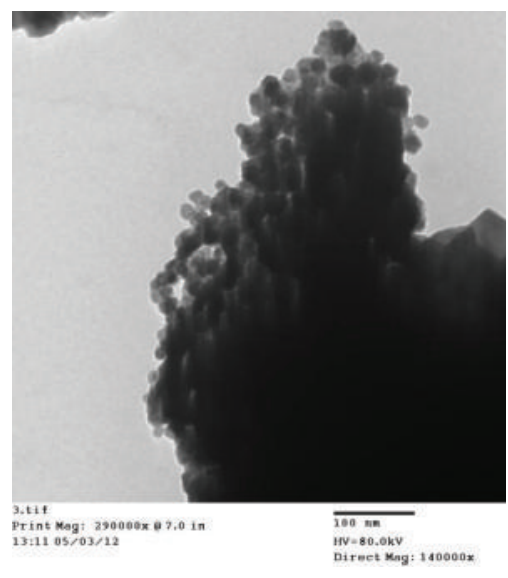

(a)

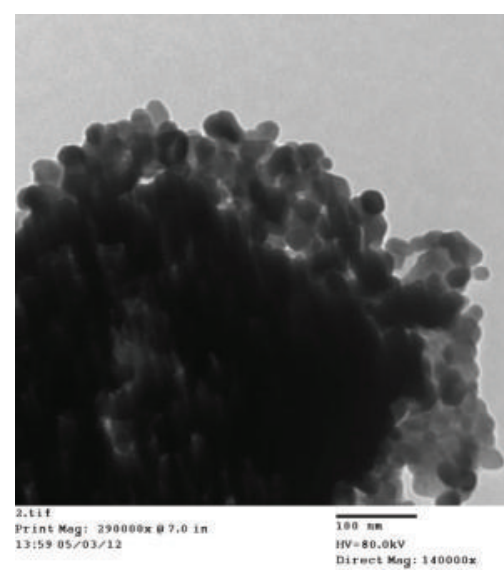

(b)

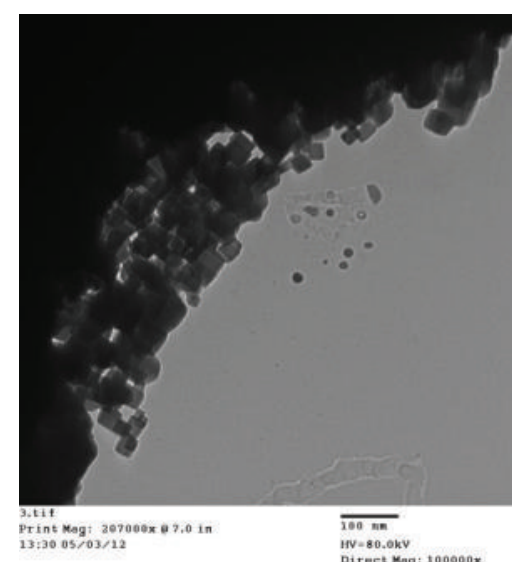

(c)

FIGURE 9: TEM micrographs of as-prepared nanocrystalline $\mathrm{Co}_{3} \mathrm{O}_{4}$ at different sucrose to cobalt molar ratios, (a) 0.5 , (b) 1 , (c) and 5, being calcined at $400^{\circ} \mathrm{C}$.

bands at $565\left(v_{1}\right)$ and $661\left(v_{2}\right) \mathrm{cm}^{-1}$, which originate from the stretching vibrations of the cobalt-oxygen bond and confirm the formation of $\mathrm{Co}_{3} \mathrm{O}_{4}$ spinel oxide.

\subsection{Electron Microscopy (SEM and TEM). Figure 7 shows} SEM of as-prepared nanocrystalline $\mathrm{Co}_{3} \mathrm{O}_{4}$ at different sucrose-to-cobalt nitrate molar ratios from 0.5 to 5 (Figures $7(\mathrm{a})-7(\mathrm{c}))$, being calcined at $400^{\circ} \mathrm{C}$. Inspection of this figure manifests that the prepared spinel $\mathrm{Co}_{3} \mathrm{O}_{4}$ shows a porous network as a consequence of the gases escaping during the combustion process. It can be seen that the samples are extremely uniform with well-defined morphology of each particle. Micrograph of sample at lower F/O value (Figure 7(a)) shows relatively small crystals having few randomly distributed pores with superficial roughening and rounding of the crystal edges. Increasing the molar ratio till 5 is accompanied by the formation of larger agglomerates of crystals having large randomly distributed pores. Figure 8 depicts SEM of as-prepared nanocrystalline $\mathrm{Co}_{3} \mathrm{O}_{4}$ using sucrose-to-cobalt nitrate molar ratio of 0.5 being calcined at $1000^{\circ} \mathrm{C}$. In comparison with the micrograph of the sample having F/O ratio of 0.5 , Figure $7(\mathrm{a})$, it is obvious that with increasing the calcination temperature the particles become bigger.

Figure 9 shows TEM nanographs of as-prepared nanocrystalline $\mathrm{Co}_{3} \mathrm{O}_{4}$ at sucrose-to-cobalt nitrate molar ratios of 0.5 (a), 1 (b), and 5 (c) being calcined at $400^{\circ} \mathrm{C}$. The TEM images reveal the nanocrystalline nature of the prepared $\mathrm{Co}_{3} \mathrm{O}_{4}$ spinel. It is obvious that the sizes of the particles vary with changing the $\mathrm{F} / \mathrm{O}$ values. The particle sizes of sample at F/O molar ratio of 0.5 , Figure $9(a)$, are in the range of $13-25 \mathrm{~nm}$. These results are in a good agreement with the sizes determined from XRD analysis by Scherrer's equation (Table 1). In addition, the particles seemed uniform and quasispherical in shape with weak agglomeration. Moreover, increasing the molar ratio from 0.5 to 1 is accompanied by increasing the particle size, Figure 9(b). However, the particles are still quasispherical

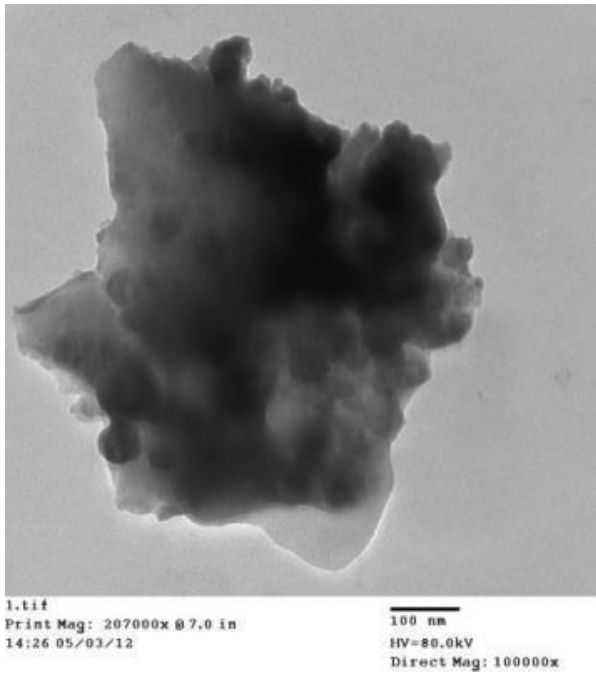

FIGURE 10: TEM of as-prepared nanocrystalline $\mathrm{Co}_{3} \mathrm{O}_{4}$ using sucrose-to-cobalt nitrate molar ratio of 0.5 being calcined at $1000^{\circ} \mathrm{C}$.

in shape, but the sizes are in the range of $21-32 \mathrm{~nm}$, and the degree of agglomeration is increased. In addition, further increasing the molar ratio to 5, Figure 9(c), is accompanied by a change from quasispherical to cubic shape and a small decrease in the particle sizes. From Figure 9(c), it is obvious that the particle sizes are in the range $20-28 \mathrm{~nm}$, which again is in a good agreement with the size determined from XRD analysis (Table 1).

Figure 10 shows TEM micrographs of as-prepared $\mathrm{Co}_{3} \mathrm{O}_{4}$ at $\mathrm{F} / \mathrm{O}$ molar ratio of 0.5 calcined at $1000^{\circ} \mathrm{C}$. Inspection of Figure 10 revealed that thermal treatment of the precursor at elevated temperatures plays a significant role on the variation of particle size and morphology of $\mathrm{Co}_{3} \mathrm{O}_{4}$ spinel. In this case, it could be seen that the particle size is in the range of $28-31 \mathrm{~nm}$, which is again in close agreement with the sizes determined from XRD analysis (Table 2). Particles of $\mathrm{Co}_{3} \mathrm{O}_{4}$ calcined at elevated temperatures are more agglomerated 
than that at lower ones (Figure 9). As a conclusion, the F/O ratio has clearly an important role on the structural and morphological properties of the powders. Low F/O ratios are recommended in this case in order to avoid agglomeration of the particles and to obtain powders with small particle size. Also, products with low calcination temperatures are recommended for the same reason.

\section{Conclusions}

It is well known that combustion synthesis is an efficient, quick, simple, low cost, and straightforward method for preparation of nanosized materials at lower temperatures. In this work, we have prepared spinel $\mathrm{Co}_{3} \mathrm{O}_{4}$ employing solution combustion synthesis using sucrose as a fuel. Sucrose content is the key factor that controls the formation of reduced oxidation state compounds such as $\mathrm{CoO}$ phase. The ratio of the fuel to nitrates dramatically influenced the phase formation of the final products and the particle size. When the ratio of fuel to nitrates was $2-5$, the final products were attributed to $\mathrm{Co}_{3} \mathrm{O}_{4}$ and $\mathrm{CoO}$ phases, but at lower (0.51) or higher ratios (8-16), the final product was mainly spinel $\mathrm{Co}_{3} \mathrm{O}_{4}$ phase. The morphology of the as-prepared $\mathrm{Co}_{3} \mathrm{O}_{4}$ is quasispherical at lower sucrose/cobalt nitrate ratio, while at higher ratio is cubic. The calcined powders showed the presence of regular particles, with narrow particle size distribution. In addition, this methodology can lead the system to a good chemical homogeneity as the reagents were mixed in an aqueous solution.

\section{References}

[1] B. M. Abu-Zied and S. A. Soliman, "Nitrous oxide decomposition over $\mathrm{MCO}_{3}-\mathrm{Co}_{3} \mathrm{O}_{4}(\mathrm{M}=\mathrm{Ca}, \mathrm{Sr}, \mathrm{Ba})$ catalysts," Catalysis Letters, vol. 132, no. 3-4, pp. 299-310, 2009.

[2] W. Y. Li, L. N. Xu, and J. Chen, " $\mathrm{Co}_{3} \mathrm{O}_{4}$ nanomaterials in lithium-ion batteries and gas sensors," Advanced Functional Materials, vol. 15, no. 5, pp. 851-857, 2005.

[3] T. Maruyama and S. Arai, "Electrochromic properties of cobalt oxide thin films prepared by chemical vapor deposition," Journal of the Electrochemical Society, vol. 143, no. 4, pp. 1383-1386, 1996.

[4] P. Poizot, S. Laruelle, S. Grugeon, L. Dupont, and J. M. Tarascon, "Nano-sized transition-metal oxides as negative-electrode materials for lithium-ion batteries," Nature, vol. 407, no. 6803 , pp. 496-499, 2000.

[5] S. Noguchi and M. Mizuhashi, "Optical properties of CrCo oxide films obtained by chemical spray deposition: substrate temperature effects," Thin Solid Films, vol. 77, no. 1-3, pp. 99106, 1981.

[6] T. Sugimoto and E. Matijevic, "Colloidal cobalt hydrous oxides. Preparation and properties of monodispersed $\mathrm{Co}_{3} \mathrm{O}_{4}$," Journal of Inorganic and Nuclear Chemistry, vol. 41, no. 2, pp. 165-172, 1979.

[7] J. Feng and H. C. Zeng, "Size-controlled growth of $\mathrm{Co}_{3} \mathrm{O}_{4}$ nanocubes," Chemistry of Materials, vol. 15, no. 14, pp. 28292835, 2003.

[8] L. Ren, P. Wang, Y. Han, C. Hu, and B. Wei, "Synthesis of $\mathrm{CoC}_{2} \mathrm{O}_{4} \cdot 2 \mathrm{H}_{2} \mathrm{O}$ nanorods and their thermal decomposition to
$\mathrm{Co}_{3} \mathrm{O}_{4}$ nanoparticles," Chemical Physics Letters, vol. 476, no. 13, pp. 78-83, 2009.

[9] Y. Teng, S. Yamamoto, Y. Kusano, M. Azuma, and Y. Shimakawa, "One-pot hydrothermal synthesis of uniformly cubic $\mathrm{Co}_{3} \mathrm{O}_{4}$ nanocrystals," Materials Letters, vol. 64, no. 3, pp. 239-242, 2010.

[10] S. Thota, A. Kumar, and J. Kumar, "Optical, electrical and magnetic properties of $\mathrm{Co}_{3} \mathrm{O}_{4}$ nanocrystallites obtained by thermal decomposition of sol-gel derived oxalates," Materials Science and Engineering B, vol. 164, no. 1, pp. 30-37, 2009.

[11] J. C. Toniolo, A. S. Takimi, and C. P. Bergmann, "Nanostructured cobalt oxides $\left(\mathrm{Co}_{3} \mathrm{O}_{4}\right.$ and $\left.\mathrm{CoO}\right)$ and metallic Co powders synthesized by the solution combustion method," Materials Research Bulletin, vol. 45, no. 6, pp. 672-676, 2010.

[12] L.-H. Ai and J. Jiang, "Rapid synthesis of nanocrystalline $\mathrm{Co}_{3} \mathrm{O}_{4}$ by a microwave-assisted combustion method," Powder Technology, vol. 195, no. 1, pp. 11-14, 2009.

[13] J. Jiu, Y. Ge, X. Li, and L. Nie, "Preparation of $\mathrm{Co}_{3} \mathrm{O}_{4}$ nanoparticles by a polymer combustion route," Materials Letters, vol. 54, no. 4, pp. 260-263, 2002.

[14] L. A. Chick, L. R. Pederson, G. D. Maupin, J. L. Bates, L. E. Thomas, and G. J. Exarhos, "Glycine-nitrate combustion synthesis of oxide ceramic powders," Materials Letters, vol. 10, no. 1-2, pp. 6-12, 1990.

[15] T. I. Izaak, O. V. Babkina, A. I. Boronin, T. N. Drebushchak, A. I. Stadnichenko, and G. M. Mokrousov, "Constitution and properties of nanocomposites prepared by thermal decomposition of silver salts sorbed by polyacrylate matrix," Colloid Journal, vol. 65, no. 6, pp. 720-725, 2003.

[16] L. Xu, B. Wei, Z. Zhang, Z. Lü, H. Gao, and Y. Zhang, "Synthesis and luminescence of europium doped yttria nanophosphors via a sucrose-templated combustion method," Nanotechnology, vol. 17, no. 17, pp. 4327-4331, 2006.

[17] R. N. Das, A. Bandyopadhyay, and S. Bose, "Nanocrystalline $\alpha$ $\mathrm{Al}_{2} \mathrm{O}_{3}$ using sucrose," Journal of the American Ceramic Society, vol. 84, no. 10, pp. 2421-2423, 2001.

[18] M. G. Lazarraga, L. Pascual, H. Gadjov et al., "Nanosize $\mathrm{LiNi}_{y} \mathrm{Mn}_{2-y} \mathrm{O}_{4}(0<\mathrm{y} \leq 0.5)$ spinels synthesized by a sucroseaided combustion method. Characterization and electrochemical performance," Journal of Materials Chemistry, vol. 14, no. 10, pp. 1640-1647, 2004.

[19] Y. J. Wu, A. Bandyopadhyay, and S. Bose, "Processing of alumina and zirconia nano-powders and compacts," Materials Science and Engineering A, vol. 380, no. 1-2, pp. 349-355, 2004.

[20] J. M. Amarilla, R. M. Rojas, and J. M. Rojo, "Understanding the sucrose-assisted combustion method: effects of the atmosphere and fuel amount on the synthesis and electrochemical performances of $\mathrm{LiNi}_{0.5} \mathrm{Mn}_{1.5} \mathrm{O}_{4}$ spinel," Journal of Power Sources, vol. 196, no. 14, pp. 5951-5959, 2011.

[21] N. M. Ghoneim, S. Hanafi, and S. A. Abo El-Enein, "Characteristics and effect of thermal treatment on surface texture of ultrafine zirconia powders," Journal of Materials Science, vol. 22, no. 3, pp. 791-797, 1987.

[22] A. Cabot, J. Arbiol, E. Rossinyol, J. R. Morante, F. Chen, and M. Liu, "Synthesis of tin oxide nanostructures with controlled particle size using mesoporous frameworks," Electrochemical and Solid-State Letters, vol. 7, no. 5, pp. G93-G97, 2004.

[23] J. Lu and Z. Z. Fang J, "Synthesis and characterization of nanoscaled cerium (IV) oxide via a solid-state mechanochemical method," Journal of the American Ceramic Society, vol. 89, no. 3, pp. 842-847, 2006. 

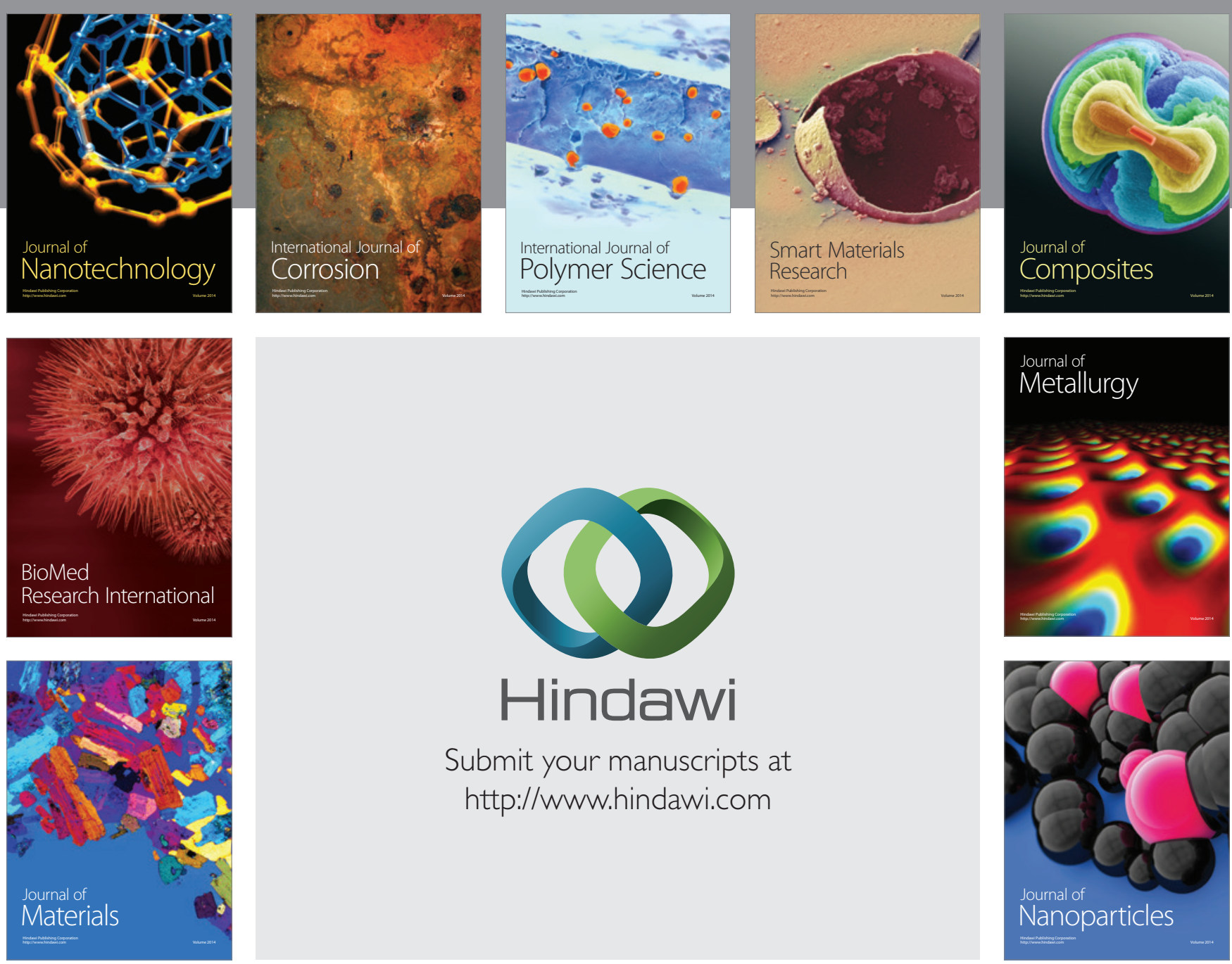

Submit your manuscripts at http://www.hindawi.com
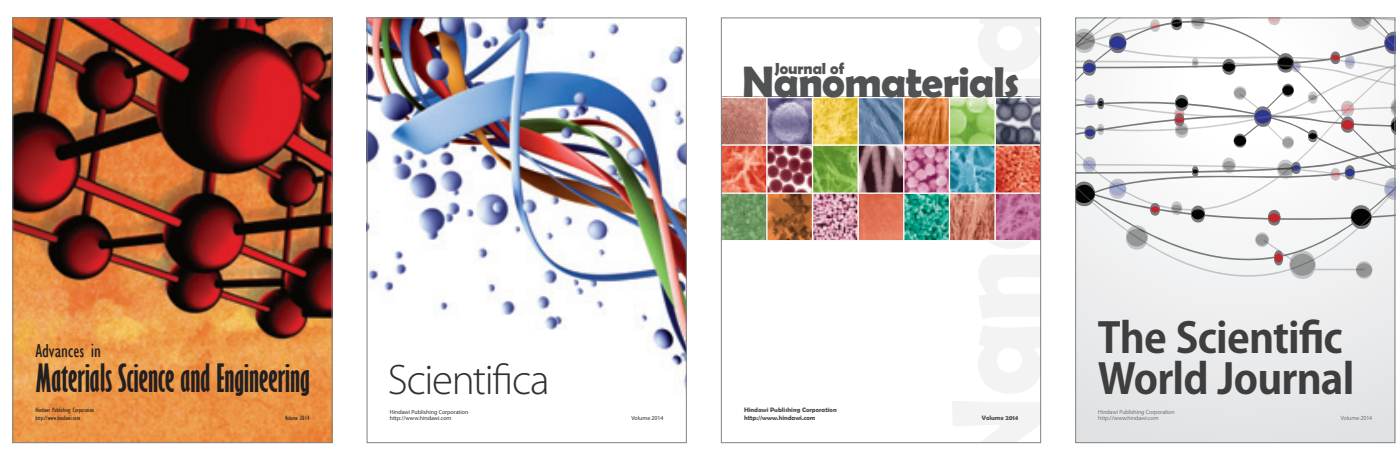

\section{The Scientific World Journal}
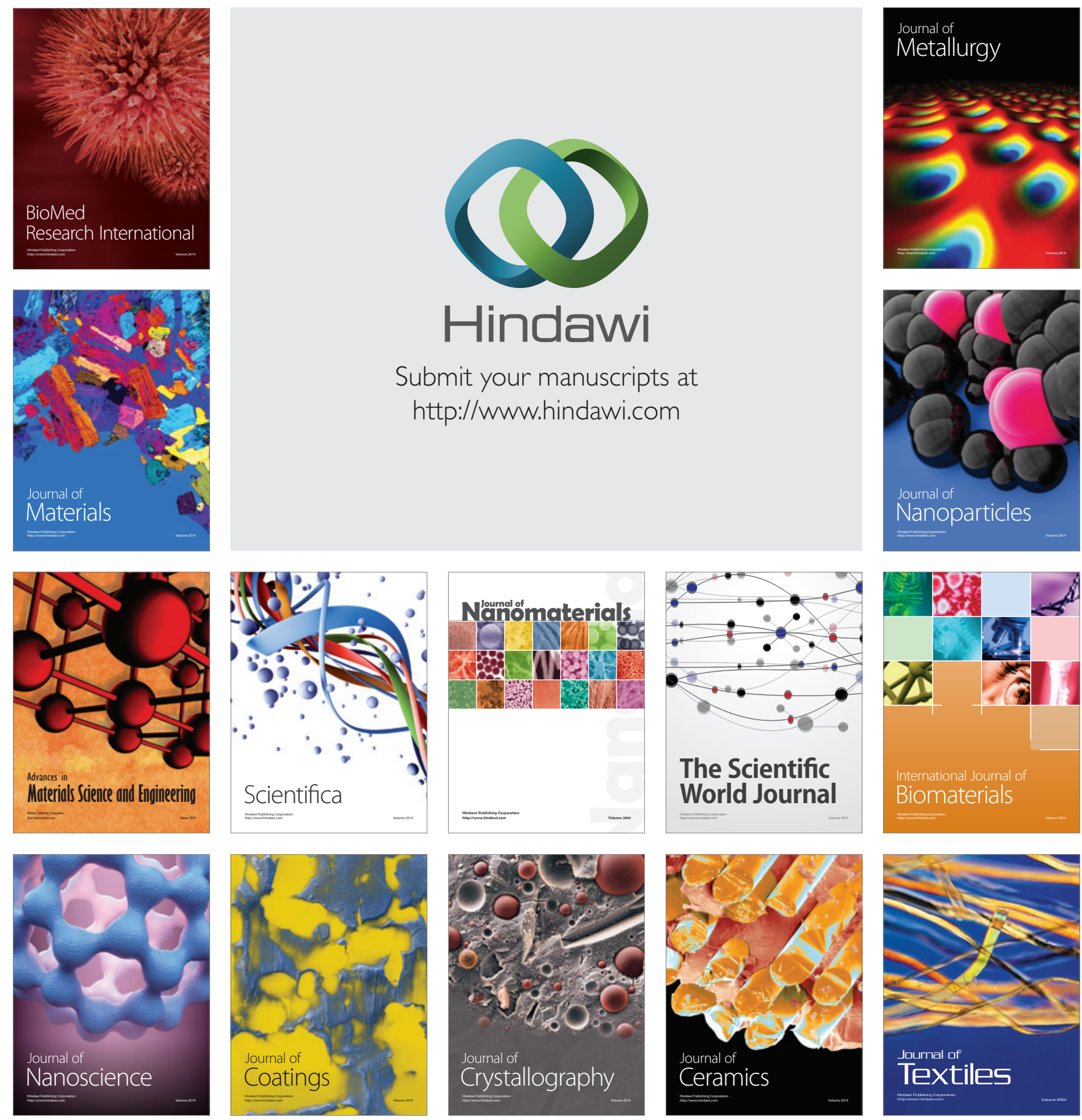